\title{
Model for Causes Elimination of Staff Resistance to Innovative Change: evidence from Lithuanian Health Care Institutions
}

\author{
Rolandas Drejeris ${ }^{1 *}$, Egle Drejeriene ${ }^{2}$ \\ 1 Vytautas Magnus university, Kaunas, Lithuania; rolandas.drejeris@vdu.lt \\ 2 Lithuanian university of health sciences, Kaunas, Lithuania; edrejeriene@gmail.com \\ * Correspondence: rolandas.drejeris@vdu.lt; Tel.: +370611 50872.
}

\begin{abstract}
Frequent employee resistance to innovation is one of the main barriers of change failure in a health care organization and one of the negative stimuli of employment relationships. Identifying the reasons of resistance is a topical issue for every organization, as the speed of change can affect their competitiveness. Consequently, it is helpful not only to know the causes of potential resistance but also to be ready to control any implicit opposition. The organizational climate and the attitude of the staff play an important role in understanding and accepting innovation. Purpose of the study is to develop a model, which would facilitate the choice of an appropriate strategy necessary to enable the health care organization to eliminate or at least to reduce resistance to often essential innovative changes. The article analyses the root causes of resistance and identifies strategies that help to mitigate or eliminate staff resistance for innovation. Use of suggested model can make easier reducing staff resistance to change processes and thus speed up the implementation of innovations. This methodology can be used to eliminate the reasons for staff resistance to change in health care institutions of different countries, but it was tested in Lithuania and achieved good enough results.
\end{abstract}

Keywords: innovation, resistance, staff behavior, employment relationship, strategy, organizational climate

\section{Introduction}

A constantly developing and changing environment is susceptible to affect organizational processes. Therefore, nowadays, in order to adjust to the environment, business, educational, medical and other organizations are forced to introduce innovations, to change/upgrade production processes, to implement cutting-edge technologies, and sometimes even to choose new fields of activity. Each health care organization has to learn (and to know how) to receive innovation, accept it as a positive challenge and manage the activities of the organization accordingly. The most commonly reported benefits for an innovative enterprise include an increased market share, faster growth of the enterprise, increased profitability, promotion of the need for internal changes in the organization, better opportunities for planning new product development, access to the benefits of the latest medical technologies, increased competitiveness, a better image of the health care institution, good repute of the undertaking, and a manifestation of competence. Proper planning as well as assessment of the current situation and the capabilities of the organization are required to enjoy the above benefits and thus to justify the need for innovation. Many authors argue that innovation is always appropriate, regardless of the existing situation. However, before any innovation is introduced, the costs, risk, and consequences must be planned and analyzed in great detail [1]. Innovation in an organization is often followed by team and staff 
resistance, which can hinder innovation [2], while the time lost in the competition may lead to unsatisfactory performance of the organization. In the innovation process, resistance emerges before innovation is implemented [3,4]. It is the duty of the management to ensure a favorable and positive microclimate and to support and encourage the staff to contribute to innovation, because, on the other hand, delaying to pursue innovative activity and doing nothing can also represent a risk especially for the health care organization.

Scientific literature does not present any system analysis of staff resistance, which could be used by organization managers for choosing efficient staff resistance to innovation mitigation measures. Moreover, there is no single proper definition of the innovation term. Some authors offer quite comprehensive and expanded definitions, while others suggest quite concise ones. Innovation can be viewed as a phenomenon and as a process. In the first instance, innovation means any targeted change (including new medical product development), which aims at altering the condition of the investigated object by introducing improvements. In the second case, it is a process, which includes research, development, control, and stable functioning aimed at a specific effect. Given that a process is some health care activity, it can be agreed upon the definition that innovation means activities aimed at the utilization of research results and inventions with a view to developing and updating the range of products/services, upgrading technologies and production followed by stepping up in domestic and global health care markets. On the organizational level, innovation determines whether or not the enterprise is going to be successful [5].

The definition of innovation can be summarized as follows: innovation in a health care consists generally speaking in complex creation, development, wide acceptance, and efficient use of novelties in different fields of human activity. Implementation of innovations in an organization always means a certain degree of change. Many researchers emphasize that the main barrier to the innovative processes is staff resistance to changes. Fischer et al. [6] particularly agree with this approach and emphasize the importance of the selection of an appropriate strategy in the innovation process. How to address barriers to innovation? Both business practitioners and academics of health care institutions are concerned with this question. Almost always the main barrier to the innovative processes is staff resistance to changes. There is no methodology yet to eliminate this negative phenomenon especially appropriate for health care organizations.

The purpose of this article is to develop a model, which would facilitate the choice of an appropriate strategy necessary to enable the organization to eliminate or at least to reduce resistance to often essential innovative changes in the health care institutions.

\section{Materials and Methods}

The need and efficiency of one or another strategy is determined by the specific nature of the enterprise engaged in innovation. Furthermore, the choice of a strategy depends on the psychological situation in the organization, the organizational culture, the attitude of the management, the staff innovativeness, the specific nature of the company, and many other aspects. To create a model determining specific actions aimed at the mitigation of staff resistance to innovation, we needed to produce a questionnaire for both the managers and the employees. Numerous literature sources were analyzed, synthesized of different ap- 
proaches, then critical evaluated in order to find information on causes of resistance to innovation. The obtained information was systematized and the determined causes were grouped. The provided analysis of the causes of staff resistance to innovative change enabled to think and highlight the potential strategic solutions aimed at the elimination of the said causes or mitigation of the negative impact of this phenomenon. On the basis of information available in scientific literature, potential strategic actions enabling elimination or at least reduction of the impact of such causes were identified. It was found that in order to eliminate some identified causes the different methods can be used. The information gathered in this way allowed for appropriate preparation for the staff survey. The model was formed on the basis of the empirical research. A staff survey in two Lithuanian primary health care clinics in the biggest cities (Vilnius and Kaunas) after consent of managerial persons was conducted. As a result of survey the necessary model was created. In the proposed model, the components are arranged following on the survey analysis results.

\section{Results}

As mentioned in the previous section identification the causes of resistance to innovate is necessary. In order to format the model, the actions, which will help eliminate determined causes must be selected as well.

\subsection{Causes of resistance to innovation}

"Resistance to change is a natural human reaction or a frequent response of the company members to any attempts to introduce changes or to disturb the equilibrium in the living conditions or organizational activity" [7]. There are different reasons why employees resist change. The phenomenon of resistance was already noted by N. Machiavelli [8: 220], who said that "there is nothing more difficult to take in hand, more dangerous to conduct, or more uncertain in its success, than to take the lead in the introduction of a new order of things. This is because the innovator has for enemies all those who have done well under the old conditions, and not very active defenders in those who may do well under the new." The main subject of innovative activities is a person, a leader, subordinate staff. It is a complex live system characterized by numerous somatic, physiological and mental features. Each person has an individual compilation of such features interacting with the natural and societal environment in their own way. Consequently, a person, as a whole of somatic, physiological and psychological characteristics, related to the natural and societal environment, can be called an individual. To introduce innovative activities in a team, it is important to understand that each individual (in this case an employee of clinics) is going to respond to innovation in a different way. "Leaders have to create work atmosphere where employees feel psychologically safe while meeting new challenges and assuming an interpersonal risk and where they feel properly valued" [9]. This means that leaders of organizations play an important role in mitigating resistance even though it is often them who initiates innovation. So, what should leaders do in order to mitigate staff resistance to innovation and to get employees involved in innovative activities?

In the process of building an innovative activity team, it is vital to consider that not only each person has a different temperament and character, but also different approaches to 
innovation. In an enterprise, innovation has to be forward planned and the staff has to be provided with all the necessary information and training.

Numerous authors provide different causes of resistance to innovation, which can be summarized and grouped as follows:

1. Employees are psychologically unprepared to understand changes. The team members in an organization are often individuals of different types, who are required for the performance of different tasks [10,11]. Due to their different personal traits, characters, and attitudes towards values, some team members will feel better psychologically prepared for new challenges than others [12]. Consequently, it is important to address the psychological readiness of the employees, which, said authors, link to the leaders' efforts to improve the microclimate of the organization and to promote teamwork. Usually psychological readiness to face change-related challenges is an individual trait of a person and since individuals can determine the state of mind in a team psychological readiness is a major aspect in innovation [13]. That means that changes in an organization can cause stress among its members, where stressed team members will express a negative opinion about the forthcoming changes and thus will worsen the psychological readiness of the team. The ability to cope with stress situation is therefore an indicator of the team's inclination to meet such challenges and the psychological climate in particular has a major impact in staying free from adverse moods in the team.

2. Inertia, adaptation to the old practices and procedures. Practices standing for several years in a row and never changing jobs eventually place the employees in a state of inertia, with their motivation level being very weak or going weaker. Managers' habit to avoid getting employees stressed with new tasks requiring a lot of thinking, analyzing and adjusting to novelties is detrimental to the team cohesion because a decision to introduce change can lead to resistance if there are going to be attempts to get them out of the established practices and to involve them in innovation [14].

With regard to corporate governance issues, the classical management theory and practice generally focus on a relatively permanent environment and regularly repeated actions by both ordinary employees and the managers. According to Sergeeva, Trifilova [15], the basis for the corporate governance structure, which was created and adopted long ago and which requires a clear and precise responsibility and function-sharing as well as coordination of coherent joint activities, prevents scientific development from being introduced in commercial activities as the employees are used to performing the same tasks over and over again. The mentioned authors also highlight that habits and an established order cause a lot of problems in implementing innovations. The most hostile employees include those who have been working for the same enterprise and in the same position for a long time, do not feel internal interest in new discoveries related to their job, and have no internal motivation for pursuing a career or personal development.

Teaching or changing employees, who do not want to try out new procedures or to provide a new service, is never easy as they will always attempt to resist such change [11]. The researchers were right in saying that such group of co-workers requires special and sensitive attention from the management in choosing relevant tasks and creating an interest in innovation. 
3. Fear of potential failures. All motivated employees want to carry out their tasks with a great deal of commitment, however, practice shows that there are cases when mistakes lead to negative consequences, such as demotion or removal from duty. Therefore, employees are more or less afraid to err. In the context of change and a renewal of activities the probability of making an error increases due to the lack of experience [16,17]. Fear of failure is particularly prevalent among employees, who used to be particularly successful prior to innovation, felt safe, influential and in control of the situation. Such employees are likely to resist change as they will be afraid that in the future they might be less able to deal with their tasks [18]. Furthermore, the perception of a failure differs and it depends on the attitude and personal characteristics of an individual. Some people treat an unsuccessful attempt to immediately achieve a maximum perfect result and a need to make some corrections and amendments as a failure, while others consider improvements to the outcomes of their work as a success. The fear of failure becomes even stronger if the new plans of the enterprise are rather vague and they are rather a rumor than information obtained from the superiors. The leaders must identify such persons and take special care in preparing them for changes. Commendations by co-workers, explanation of the results and encouragement not to let negative emotions guide play a positive role in dealing with the fear of failure.

4. Another group of causes is identified by Loewe \& Dominiquini [19], who define them as "secondary emotional consequences, i.e. lower self-confidence and influence on others, a potential increase in responsibility and stress". Each staff member is individual, they come to the organization from different backgrounds, they have different marital status, personal qualities and likes. The emotions employees bring to the working environment are not necessarily positive. Sometimes a negative response to innovation can lie in an unsuccessful personal life of the employee, which means that innovation will represent an additional stress factor in the context of their emotions. Baer and Frese [20,21] argue that in such case the stress encountered beyond the enterprise will become more severe only by learning about the change to be introduced in the organization. Frequently stress takes the form of reduced self-confidence and increased private stress. Externally acquired private stress of an employee in some health care institutions usually leads to resistance to changes and inclination to oppose, which is represented by potentially reduced self-confidence and increased private stress $[19,21]$. The involvement of such employees in the processes of change requires most effort as such employees consider their personal psychological condition to be prevalent in any situation.

5. Lack of confidence in the management. A manager can be the leader who shows the way forward to the whole team, however, there are managers who are incompetent in the performance of their duties or who have made decisions that the subordinate staff find improper, who have divided the team or lost the confidence of a number of employees. The lack of confidence resulting from the manager's actions will lead to resistance and doubts as to the manager's new ideas [22]. Lack of confidence is another major cause of staff resistance to change. Successful organizational change cannot root in an organization lacking of trust climate. Confidence includes belief that the management's intentions and conduct towards the employees will not disappoint. Organizations, where the confidence level is high and employees are treated with dignity and 
respect, suffer less resistance to change. It was found that managers with a high level of professionalism generally inspire more confidence, which means that professional development and continuing education is vital for organization managers [23, 24]. Once mutual confidence between the manager and the subordinate staff disappears, any intention to innovate can will not encourage to support innovation, if any collapse [20]. If employees are confronted with employment uncertainty and the perception of insecurity results from their low confidence in managers' decisions, employees tend to focus on seeking new employment and the negative thinking about the current organization). 6. A specific type of contract with the employer. Seasonal or fixed-term work can be performed by temporary workers, who know that they will work for the organization only until the expiry of the contract and afterwards they will have to seek employment again. Due to the awareness of the temporary nature, the motivation of the temporary staff will not be so strong and therefore it is highly likely that they will resist proposed innovation. Pentland [25] notes that actions of team members are always directed towards a situation they can benefit from. Research shows that the nature of the employment contract (shortterm or long-term) between the employee and the employer affect the efforts to contribute to the essential welfare of the enterprise. Conner and Prahalad [26] further declare that the type of an employment contract does not only affect the efforts but also has an impact on personal fulfilment of the individual at the workplace. It is therefore logical that an employee, who has entered into a short-term or seasonal contract, will not show strong interest in taking pains to support corporate objectives, but Tsoukas [27] nevertheless argues that "a person's understanding is implicit in the activity in which he engages" and thus the efforts of both temporary and permanent employees should be subject to an objective judgement as they depend on the general climate rather than on the individual situation of an employee. The perception of temporary employment often limits the employee's initiative, in particular their willingness to learn new skills, where such skills will be necessary in the short term only but will not be relevant in further activities of the person. It is for these reasons that such employees resist organizational change and there is only one strategy focused on agreement that is usually efficient [28]. Furthermore, temporary workers also usually have a narrow-minded attitude towards publicity and promotion of a new product [13].

7. Lack of work under new conditions skills. According to Laukkanen \& Kiviniemi [29] empowerment and training in implementing innovations can help some members adapt to innovation, however the lack of certain skills can lead to reluctance to develop themselves. Long-time employees in particular do not want to recognise the lack of work under new conditions skills. Such people usually reject the need of innovation and avoid tackling innovation-related issues [30]. Unwillingness to develop indicates skill gaps and leads to evasion of responsibility. Such persons are plainly opposed to innovation whereas the situation created thereby has a negative impact on other team members [11]. The lack of work under new conditions skills forces older long-time employees to improve knowledge and learn. This circumstance clearly demonstrates that they are insufficiently qualified and the unwillingness to acknowledge this fact can lead to the sense of helplessness, which promotes resistance to innovation at the undertaking [29]. However, even if broader-minded employees decide to start improving qualifications, they have to acknowledge their lack of skills and this circumstance makes them 
feel bad in front of their colleagues. Then resistance to change becomes some kind of a way out of such situation.

8. Personal conflicts with innovators. Previous disagreements among team members and related negative associations will hardly lead to any support for innovation suggested by the opposing side of the former conflict [30]. According to Patricio et al. [11], innovative actions often fail due to psychological and organizational factors resulting in conflicts among team members, rather than on account of technical or financial matters. Such conflicts always suppress the development and the implementation of any innovative ideas. Change originators and new idea generators are often viewed sceptically and with envy and such circumstances lead to conflict situations as the lack of knowledge and skills among the opponents of change prevents them from being innovative, even if they want to. Moreover, employees who have previous conflicts with the current innovation originators resist change because if they recognised change they would appear to admit their loss in the previous conflict [30]. It is essential to create a balance between employees who are skeptical or optimistic about new ideas as any extreme is detrimental to innovation.

9. Destruction of work groups that are coherent and banded together (reorganization). In the long run, the members of a successful work group become close friends and create a comfortable microclimate in the organization. Any attempt to regroup, to replace or to remove old group members will result in dissatisfaction of other members. Employees who are successfully working in their work groups will be interested in resisting to change in order to protect the interests of the group, teammates and colleagues [31]. It is normal that employees resist to change in order to protect their colleagues. That happens because they are sympathetic to their friends, who might be downgraded or dismissed as a result of the reorganization because the new system might require employees with some special skills and such employees will be hired to replace the old ones. Destruction of a successful and coherent work group means reshaping of such groups, while reactivation of a sustainable performance of a reformed group requires time and effort. Middle managers also resist such change in order to protect their work groups or friends. All the above behavioral patterns can impede any change in the organization. Consequently, employees must get regular updates on successful decisions and achievements of the organization.

10. Weak planning. Not all organizations enjoy good communication and timely information transfer from the top management to the lower levels. Sometimes an irrelevant structure or negligence result in a situation when employees in less senior positions learn about planned changes only after such changes have been introduced. In the absence of relevant information, preparation and training, employees are likely to be negative and hostile to innovation. A well-prepared plan of corporate changes will always help the employees to recognize their need and to understand the existing situation. Not all organizations have proper and qualified managers, who have experience in innovation planning. An inadequately drafted plan is likely to result in disrupted implementation of innovations. Usually the staff dealing with innovations is accused of such situation and then such employees start opposing any change. Inadequate planning can cause suspension or termination of innovation, including financial costs to the enterprise [32]. A failed first attempt of innovation resulting from 
ill-conceived work is followed by staff resistance. Moreover, resistance to innovation can also be caused by an innovation process that is too long, when the staff have to perform tiresome routine tasks.

11. Lack of innovation-related information. This cause arises in unfavorable situations, when the management makes a unilateral decision to introduce innovations swiftly without consulting or at least informing the company staff. Lack of information has a particularly negative impact on speeding up innovation, when the objectives of the innovative activity fail to be explained. Lack of information as a cause of resistance to innovation is closely related to other causes described above. Aside from that, it can be easily eliminated and also treated as a separate cause since it is obvious that it is important to have as much information on planned change as possible because lack of such information can only lead to confusion and serve as the basis for the emergence of other aforementioned causes [16, 17].

Most of the said causes of resistance can be addressed by analyzing their origin and planning appropriate strategies in order to eliminate the causes or to mitigate their effects. Daveri \& Parisi [33] and Lichtenthaler [34] argue that a proper choice of the strategy of staff preparation enables to reduce the costs of innovation

3.2 Discussion about requirements for the causes elimination model of the staff resistance to innovative change

An important indicator of innovation promotion is a focus on inviting all colleagues to cooperate in good faith and to engage in team work. Knowledge about the tasks performed by other colleagues, trust and mutual support direct towards a successful completion of work [35]. However, just inviting is not enough. Therefore, managers should focus on the establishment of a motivation system that would work to the satisfaction of both the employees and the management. In an environment, where initiative and creativity are encouraged and procedures are observed, objectives are achieved in less time [36]. In such environment, the staff of the organization should feel psychologically fit and ready to take on challenges.

The problem of solving the said problems is a highly complex process that requires not so much financial resources as time and permanent cooperation of the innovation managers with the staff. The leading staff of an organization should not expect to change the corporate culture in one day. But they have to create a "safety zone" for innovators and to be prepared for "mistakes" as an unavoidable part of innovation [23]. Otherwise fear will prevent from moving towards the implementation of new ideas. Mitigation of the causes of resistance to innovation has to be prepared and pre-planned through one or more strategies. The purpose of any strategy aimed at the reduction of resistance is to help the members of an organization not only to understand the root causes of the need for a change, not only to avoid resistance but also to eliminate conditions that can lead to resistance. A strategy is a long-term action plan directed towards achieving a certain goal. Therefore, the 
measures of elimination of the causes of resistance to innovation must be consistent, preplanned, flexible, and based on long-term strategic decisions. A well-chosen strategy will enable to better adjust to external impacts and to deal with internal misunderstandings.

A strategy is the key action program of an organization, which establishes the priorities of long-term objectives and the resources required to achieve such objectives. Each strategy is unique and it is prepared for a specific action and a specific period of time. A strategy is developed by the top managers, whereas the implementation involves managers of all levels. It has already been said that leaders of organizations, the way they treat employees, how they understand the need of change, and their environmental responsibility play an important role in mitigating resistance. The following strategies are suggested for dealing with the said situations:

1. Training and awareness-raising involves from face-to-face and group discussion to special reports. This strategy can be applied when there are information gaps in the organization. It is a particularly efficient strategy because once the members of an organization are persuaded later they often find new ways for innovation. Unfortunately, it is very timeconsuming and takes too many people, who are even unrelated to innovation, from their jobs. This strategy is efficient in many instances, because employees often resist change simply because they do not know the likely outcomes of change. Respective new skills training and awareness-raising regarding potentially emerging new opportunities usually help to overcome staff resistance to innovation. This strategy is also efficient to cope with the fear of failure and it is suitable for dealing with emotional crisis in the organization. The training and awareness-raising strategy is more time-consuming but it requires less material resources and therefore it is most widely used with a view to resistance mitigation [37]. This is the best strategy when the cause of resistance is a specific type of contract with the employer. In this case it is usually enough just to raise the employee's awareness and to explain the positive consequences of change and the resistance immediately decreases.

2. Networking means the broadest possible staff engagement in innovation and apportioning responsibility for innovation success among as many participants as possible. This strategy is used not only in the cases when there are information gaps but also when the participants of innovative activity can have greater influence on the success. This strategy has a motivating character. When employees are given responsibility for appropriate performance of certain actions, the people will feel better in innovative activity and will always be happier with the success of change than those who have not assumed responsibility. This strategy is appropriate where work groups coherent with respect to their approach to activities are destructed owing to the nature of the activities [31]. Designation of several persons responsible for a similar activity usually results in the emergence of new informal groups that are characterized by being coherent and banded together in addressing the achievement of a new change-related objective. If the coalescence of the staff for the purpose of achieving a common goal fails, all that remains is to negotiate with those, who have not assumed the responsibility for the possibilities of the future activity, and to agree on innovation.

3. An incentive strategy is based on the constant attention focus on behalf of the top management and the material and non-material incentives for the participants of the innovative activity. This strategy is to be used when the critical issues are related to the 
adaptation of the people and mostly it is rather efficient. The incentive strategy leads to competition among employees and therefore it is not suitable for all team members. This strategy has to be carefully applied to promote the most innovative employees, to grant them an increase in salary or to provide other incentives to compensate for their engagement in innovation. The incentive strategy is usually applied as a second strategy after lower-cost strategies fail to deliver [37]. On the other hand, Manso [37] argues that new team members often understand a possibility to learn new skills as an incentive and therefore they respond favorably to change implementation in the organization. However, an inappropriate use of the incentive strategy can give an opposite result, i.e. resistance to innovation, and for that reason managers must carefully consider the conditions of this strategy [23].

4. Negotiation and agreement strategy means that the management reaches an agreement with organization members suffering obvious inconveniences on potential compensation for such inconveniences. Frequently that is not very difficult, however, if reaching a compromise takes too long, it can become costly and it would stimulate other employees' resistance to innovation. Negotiations usually help to affect the opinion of the most negative team members with regard to change. This strategy is suitable when the staff awareness is insufficient and also it can be used if training and awareness-raising efforts fail [12]. Company managers, who are willing to introduce innovations, should identify people who might be going to experience certain inconveniences, explain them the need for change and start negotiating and seek agreement in advance before such employees start resisting.

5. Implicit and explicit compulsion when employers are threatened with dismissal, a pay cut, a reduction of growth perspectives, etc. This strategy can be used when the speed of innovation is essential and the innovators have sufficient power. That is a quick-action strategy that can overcome any resistance, yet very dangerous where it gives the key participants of innovation a feeling of animosity towards the leaders and organizers of innovation. Such strategy should be used in a very responsible manner as it can lead to stronger resistance to innovation. Therefore, this strategy should be used together with training and awareness-raising strategy aimed at even positive-minded employees. Compulsion is the last option to address resistance to change in an organization and it can be used when its necessity is obvious and when other strategies do not work. For instance, in medicine, if new treatment methods are not accepted, it can lead to compulsory use of the methods in order to improve the health of the patients [38].

The need and efficiency of one or another strategy is determined by the specific nature of the enterprise engaged in innovation. Furthermore, the choice of a strategy depends on the situation in the organization, the organizational culture and many other aspects.

\subsection{Formation the causes elimination model of the staff resistance to innovative change}

We identified a total of 11 causes and opted for 5 strategies capable to eliminate the identified causes (or to reduce the impact of the phenomenon). In this case can be stated that the research aim is to find out which strategy is the most appropriate for the elimination of certain causes. Therefore, the first question was of a general nature and it had to emphasize 
the relevance of the research. The answer to the first question had to show whether the person generally feels dissatisfaction or any psychological or other resistance to some organizational change. Further questions were to be answered only by the employees who gave a positive answer to the first question. Then the respondents were asked to rank the listed causes by their significance and to potentially specify insignificant causes (i.e. those without a significant impact). The aim of this empirical research is to identify the most significant causes, the elimination whereof by applying relevant strategies can lead to a potential removal of staff resistance, which means that consequently there will be no need for strategies aimed at the elimination of less significant causes. For that purpose, the respondents were asked to specify which strategies could eliminate the specified causes and which strategy feels to be missing.

The survey included employees of 2 private primary health care clinics chains (Affidea and Medica). They include 6 primary health care clinics, which employ 217 people. To calculated the sample size, we chose a 5\% margin of error and a 95\% confidence level and we found that we had to survey 139 employees. The questionnaire was published on special website and the respondents were sent personal requests to complete the questionnaire. 180 requests were sent by email and 140 completed questionnaires were received. The answers were received from 11 clinic or department managers and 129 ordinary employees (doctors, nurses and other staff). The results confirmed the hypothesis formulated in the thematic area of the article that most of employees of health care institutions (71\%) are not psychologically prepared to take on new challenges and therefore at least unconsciously resist them. The causes were ranked from \#1 to \#11. The respondents ranked the causes in order of importance with \#1 being the most important cause to \#11 being the least important cause.

Then the ranking numbers of each cause were summed up and the obtained sum had to show the total significance of the cause in descending order: the smallest number had to show the most significant cause. The significance of causes is provided in Table 1.

Table No 1. Employee Survey Results of Lithuanian Primary Care Institutions

\begin{tabular}{|l|l|l|l|}
\hline $\begin{array}{l}\text { Causes resulting in deliberate or unconscious resistance to inno- } \\
\text { vation challenges }\end{array}$ & $\begin{array}{l}\text { Significance } \\
\text { value }\end{array}$ & $\begin{array}{l}\text { Significance } \\
\text { rank }\end{array}$ & $\begin{array}{l}\text { The most } \\
\text { relevant } \\
\text { strategies }\end{array}$ \\
\hline Employees are psychologically unprepared to understand changes & 228 & 1 & $1 ; 3$ \\
\hline Inertia, habituation to old practices and procedures & 270 & 2 & $1 ; 2 ; 3 ; 4$ \\
\hline Fear of potential failures & 727 & 5 & $1 ; 3$ \\
\hline $\begin{array}{l}\text { Secondary emotional consequences, i.e. lower self-confidence and } \\
\text { influence on others, a potential increase in responsibility and stress }\end{array}$ & 911 & 7 & $1 ; 3$ \\
\hline \begin{tabular}{l} 
Lack of confidence in the management \\
\hline
\end{tabular} & 1224 & 11 & $1 ; 4$ \\
\hline
\end{tabular}




\begin{tabular}{|l|l|l|l|}
\hline A specific type of contract with the employer & 1088 & 9 & $4 ; 1$ \\
\hline Lack of work under new conditions skills & 1089 & 10 & $1 ; 2$ \\
\hline Personal conflicts with innovators & 1008 & 8 & $5 ; 4 ; 1$ \\
\hline Destruction of coherent and banded together work groups & 685 & 4 & $1 ; 4 ; 3$ \\
\hline Weak planning & 79 & 6 & 4 \\
\hline Lack of innovation-related information & 541 & 3 & $1 ; 4 ; 3$ \\
\hline
\end{tabular}

Furthermore, the respondents were asked to note which of the 5 listed strategies would be the most relevant in order to address the identified causes of resistance. They were asked to write the number of the most appropriate strategy next to each cause. We received only 128 properly completed questionnaires with answers to this question. The research results are presented in Table 1.

For Cause 1, the respondents mostly proposed Strategy 1 (256 times) and Strategy 3, which was indicated 184 times. For Cause 2, Strategy 1, Strategy 2, Strategy 3, and Strategy 4 were suggested in 212, 102, 90, and 56 questionnaires, respectively.

We believe, that the strategy ranking by the respondents correlates with the strategy efficiency and thus Column 6 of Table 1 was completed based on this principle.

It should be noted that the managers' and ordinary staff's answers were not substantially different, just most of the managers (84\%) suggested Strategy 5 for Cause 8, whereas only $44 \%$ of the ordinary staff found Strategy 5 efficient in addressing conflicts.

The model of the choice of the strategy for the mitigation of staff resistance to innovative change is produced basing on the data provided in Table 1 (Fig. 1). In the model, the suggested strategies are ranked according to the predicted effectiveness. Therefore, we believe that the application of the most effective strategy would lead to the desired result. In case the resistance continued, another (the second most effective) strategy would have to be applied. This can be possible if the conditions in the organization or external impacts change.

Organizations facing staff resistance to innovation can use the model to choose the best strategy depending on the root causes, which can help them eliminate or at least mitigate such resistance to innovation (Figure 1).

Our further research would focus on analysis of deeper correlations between the causes of resistance to innovation and the choice of the most efficient strategic direction, the identification of means for implementing such a strategy, and the establishment of the need for innovation intensity. The application of this model will help health care institutions to be more efficient in their innovation process by saving both time and emotional cost.

Usually the success of innovative change depends on the timing of the innovation. Although the proposed methodology has been tested in health care institutions, when applied 
in the specified sequence, it could be used in any other entities, i.e. both public and business organizations.

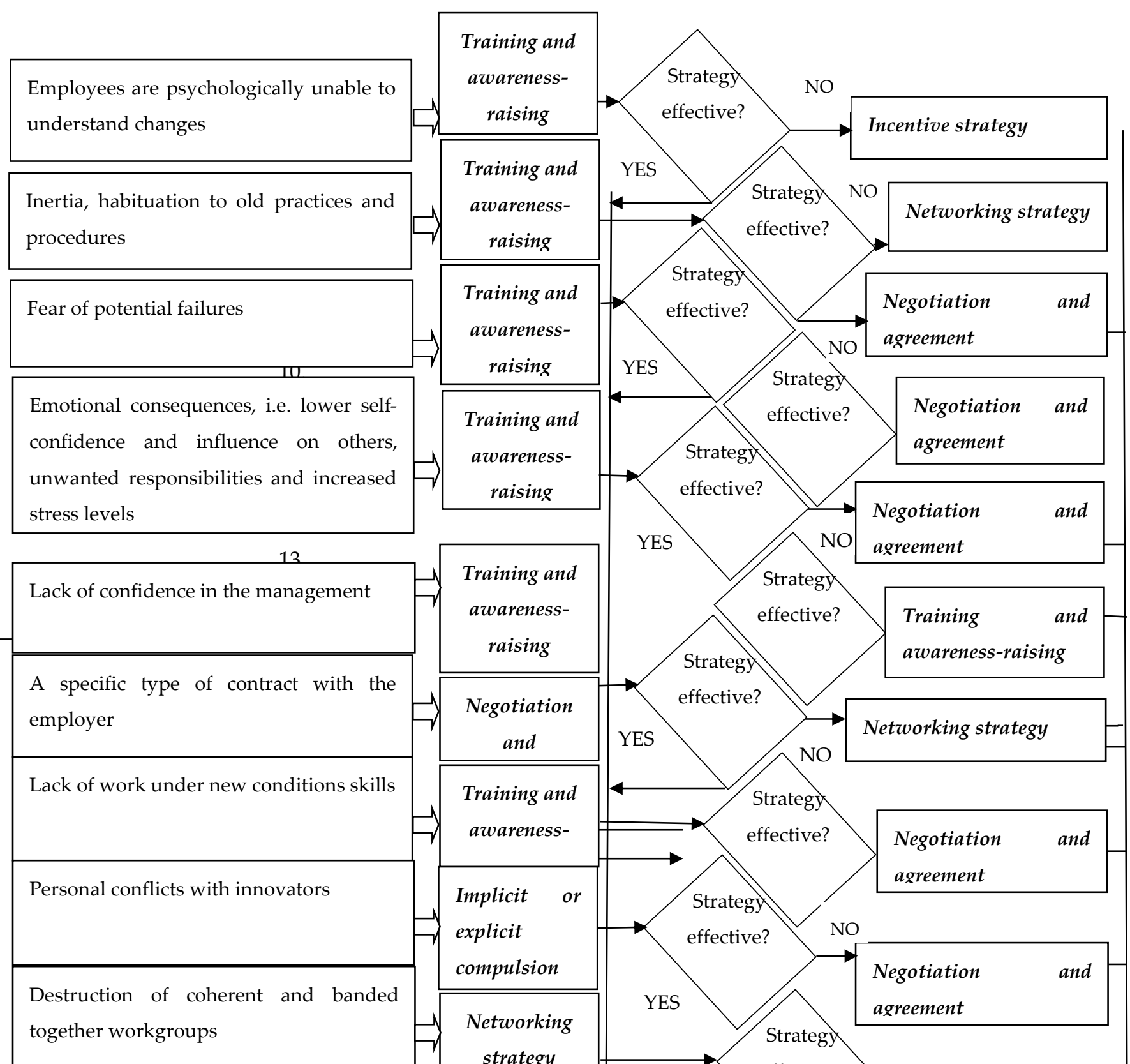


19.

It has been demonstrated that a proper choice of the strategy can lead to an improved in the psychological climate in the organization, enable to avoid conflicts and to reduce resistance to innovation. The article reviews the strategies for resistance elimination and assigns them to each specific cause.

\section{Conclussions}

People and organizations are always affected by the environment and therefore change is essential in order to adapt to the changing conditions. Innovation is one of the potential responses of an organization, however, the staff, for one reason or another, resist such innovation. Based on aggregate information from numerous sources, the article pinpoints the causes and briefly reviews possible ways to eliminate resistance to innovation.

The causes of change resistance and the suggested respective strategies were represented graphically and expressed in the form of a model, the use whereof will enhance the innovation capacity of the organization by avoiding or mitigating staff resistance. The model defines situations when several strategies are suggested for certain causes of resistance to innovation. In such case the choice of the strategy depends on the specific situation. Such use of modeling methodology can help the administrators of health care institutions to eliminate causes of staff resistance for change, and such circumstances will accelerate innovation development.

It has been demonstrated that a proper choice of the strategy can lead to an improved in the psychological climate in the organization, enable to avoid conflicts and to reduce resistance to innovation. The article reviews the strategies for resistance elimination and assigns them to each specific cause. Awareness raising is the key to overcoming resistance and promotion of the diffusion of innovation among employees. In order to reduce resistance to change, it is of particular importance that employees engaged in innovation are 
provided with correct information, are properly qualified to pursue innovative activity, and have possibilities to identify themselves with the change objectives building on a favorable climate and appropriate resources allocated for this purpose. It is the duty of the management to ensure a favorable and positive microclimate and to support and encourage the staff to contribute to innovation.

Suggested model was tested in 6 primary health care clinics in Lithuania. The results confirmed the existing desire to avoid change and identified the most effective strategies, which helped to refuse resist changes in the mentioned clinics during the pandemic.

\section{References}

1. Crossan, M. M. \& Apaydin, M. 2010. A multi-dimensional framework of organizational innovation: A systematic review of the literature. Journal of Management Studies, 47, 1154-1191.

2. Bjorn, W. A. 2006. The influence from corporate entrepreneurship and intrapreneurship on white-collar workers' employee innovation behavior. International Journal of Innovation and Learning, 3, 284-298.

3. Woodside, A. G. \& Biemans, W. G. 2005. Modeling innovation, manufacturing, diffusion and adoption/rejection processes. Journal of Business $\mathcal{E}$ Industrial Marketing, 20, 380-393.

4. Zwick ${ }_{L}$ T. 2002. Employee resistance against innovations. International Journal of Manpower, 23 542-552.

5. Crossan, M. M. \& Apaydin, M. 2010. A multi-dimensional framework of organizational innovation: A systematic review of the literature. Journal of Management Studies, 47, 1154-1191.

6. Fischer, B. D., Matthew, E. C. \& College, R. L. 2013. Management resistance to innovation. American Journal of Management, 13, 93-99.

7. Yongchuan Bao. 2009. Organizational resistance to performance-enhancing technological innovations: a motivation-threat-ability framework. Journal of Business E Industrial Marketing, 24, 119-130.

8. Denman D. S. (2019). Machiavelli and the Fortress City. Political Theory.;47, 203229.

9. Edmondson, A. 1999. Psychological safety and learning behavior in work teams. Administrative Science Quarterly, 44, 350-383.

10. Rhoda, C. J. (2010). Individual resistance to IT innovations. Communications of the ACM, 53, 144-146.

11. Patricio, R., Moreira, A., Zurlo F., \& Melazzini, M. (2020). Co-creation of new solutions through gamification: A collaborative innovation practice. Creativity and Innovation Management, 29, 1, 146-160.

12. Andrew, A. 2017. Relationship between Employee Readiness for Organizational Change and Employee Performance. Journal for Studies in Management and Planning, 3, 23-35.

13. Ostrom A.L., Fotheringham D. \& Bitner M.J. (2019) Customer Acceptance of AI in Service Encounters: Understanding Antecedents and Consequences. In: Service Science: 
Research and Innovations in the Service Economy, Vol. 2. Switzerland: Springer Publisher.

14. Heidenreich, S., Handrich, M. 2015. What about Passive Innovation Resistance? Investigating adoption-related behavior from a resistance perspective. Journal of Product Innovation Management, 32, 878-903.

15. Sergeeva, N. \& Trifilova, A. The role of storytelling in the innovation process. Creativity \& Innovation Management, 27, 489-498.

16. Heidenreich, S., Kraemer, T. \& Handrich, M. 2016. Satisfied and unwilling: exploring cognitive and situational resistance to innovations. Journal of Business Research, 69, 2440-2447.

17. Kriegesmann, B., Kley, T. \& Schwering, M. G. 2005. Creative errors and heroic failures: capturing their innovative potential. Journal of Business Strategy, 26, 5764.

18. López Ramos A., Rodriguez-Monroy C. \& Calvo-García F. (2018) Management, Innovation Capacity and Fear of Failure in a Sample of Spanish Firms. In: Viles E., Ormazábal M. \& Lleó A. (eds) Closing the Gap Between Practice and Research in Industrial Engineering. Springer: Cham.

19. Loewe, P. \& Dominiquini, J. 2006. Overcoming the barriers to effective innovation. Strategy \& Leadership, 34, 24-31.

20. Baer, M. \& Frese, M. 2003. Innovation is not enough: climates for initiative and psychological safety, process innovations, and firm performance. Journal of Organizational Behavior, 24, 45-68.

21. Arnetz, J. E.; Zhdanova, L. \& Arnetz, B. B. 2016. Patient Involvement: a new source of stress in health care work? Health Communication, 31:12, 15661572. DOI: $10.1080 / 10410236.2015 .1052872$.

22. Mitchell, G. 2013. Selecting the best theory to implement planned change. Nursing Management, 20, 32-37.

23. Holmstrom, B. \& Milgrom, P. 1994. The firm as an incentive system. The American Economic Review, 84, 972-991.

24. Drejeris, R.; Bivainis, J.; Tunčikienè, Ž. \& Drejerienė, E. 2013. Determining the purposefulness of new services on the grounds of the results of quantitative analysis. Journal of Business Economics and Management, 14, 791-805.

25. Pentland, A. 2013. The data-driven society. Scientific American, 309, 78-83.

26. Conner, K. R. \& Prahalad, C. K. 1996. A resource-based theory of the firm: knowledge versus opportunism. Organization Science, 7, 477-501.

27. Tsoukas, H. 1996. The firm as a distributed knowledge system: a constructionist approach. Strategic management Journal, 17, 11-25.

28. Wheeler, A. \& Buckley, M. (2001), Examining the motivation process of temporary employees: A holistic model and research framework. Journal of Managerial Psychology, 16, 339-354.

29. Laukkanen, T. \& Kiviniemi, V. 2010. The role of information in mobile banking resistance. International Journal of Bank Marketing, 28, 372-388. 
30. Cunningham, S., Theilacker, M., Gahan, P., Callan, V., \& Rainnie, A. (2016). Skills and capabilities for Australian enterprise innovation. Australian Council of Learned Academies (ACOLA): Australia.

31. Lo, Y., Fiss, F., Rhee, E. \& Kennedy, M. (2018). Category Viability: Balanced Levels of Coherence and Distinctiveness. Academy of Management Review, 45, 291302.

32. Ziegler A. (2018) Disentangling Technological Innovations: A Micro-Econometric Analysis of their Determinants. In: Horbach J., Reif C. (eds) New Developments in Eco-Innovation Research. Sustainability and Innovation. Springer, Cham.

33. Daveri, F. \& Parisi, M. L. 2015. Experience, innovation, and productivity: empirical evidence from Italy's Slowdown. Industrial \& Labor Relations Review, 68, 889915.

34. Lichtenthaler, U. 2016. Toward an innovation-based perspective on company performance. Management Decision, 54, 66-87.

35. Staples, D. S. \& Webster, J. 2008. Exploring the effects of trust, task interdependence and virtualness on knowledge sharing in teams. Information Systems Journal, 18, 617-640.

36. Frese, M. \& Fay, D. 2001. Personal initiative: an active performance concept for work in the 21st century. Research in Organizational Behavior, 23, 133-187.

37. Manso, G. 2017. Creating Incentives for Innovation. California Management Review, 60, 18-32

38. Manning, R. M. \& Greenwood, R.M. (2019). Understanding Innovation in Homeless Service Provision: A Study of Frontline Providers' Values-Readiness for Change. Administrative Policy and Mental Health, 46, 649-659.

Authors Contributions: Conceptualization, R.D.; methodology, R.D..; software, E.D..; validation, R..D. and E.D..; formal analysis, R.D..; investigation, E.D..; resources, E.D..; visualization, E.D.; supervision, R.D..; project administration, R.D. All authors agree to the published version of the manuscript.

Funding: This research received no external funding.

Institutional Review Board Statement: The study was conducted according to the guidelines of the Declaration of Helsinki, and approved by directors of Affidea and Medica clinics.

Informed Consent Statement: Informed consent was obtained from all subjects involved in the study.

Data Availability Statement: website www.apklausa.lt. is limited for conducting research, so the information no longer exists.

Conflicts of Interest: The authors declare no conflict of interest. 